\title{
Production and application of glucose isomerase from Streptomyces enissocaesilis and amylase from Streptomyces sp. for the synthesis of high fructose corn syrup
}

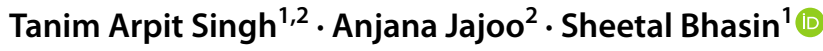

Received: 11 May 2020 / Accepted: 23 October 2020 / Published online: 9 November 2020

(c) Springer Nature Switzerland AG 2020

\begin{abstract}
This study reports Streptomyces sp. strain T.S.A.KP identified as Streptomyces enissocaesilis isolated from soil inhabiting actinobacteria of Madhya Pradesh (India) as a new actinobacterial strain for production of glucose isomerase (GI) and Streptomyces sp. strain TSA. Dm1 closely related to Streptomyces sampsonii for the production of amylase. These strains were selected from an array of 120 actinobacterial isolates, which on screening originally yielded $18 \% \mathrm{Gl}$ producers and $36 \%$ amylase producers. S. enissocaesilis yielded maximum Gl at pH 7 and $70^{\circ} \mathrm{C}$ in $120 \mathrm{~h}$. Highest amylase production from Streptomyces sp. strain TSA. Dm 1 was observed at $\mathrm{pH} 7$ and $37{ }^{\circ} \mathrm{C}$ in $96 \mathrm{~h}$. Michaelis-Menten constant $\left(K_{\mathrm{m}}\right)$ for Gl and amylase was $1.54 \mathrm{M}$ and $0.36 \mathrm{M}$, respectively. $V_{\max }$ for $\mathrm{Gl}$ was $11.76 \mathrm{U} / \mathrm{ml}$ and amylase $33 \mathrm{U} / \mathrm{ml}$. These cultures were employed for HFCS production. Saccharification of corn starch was achieved up to $90.9 \%$ by Streptomyces sp. strain TSA. Dm1, and the glucose was isomerized to $40.8 \%$ by S. enissocaesilis. Presence of glucose and fructose in HFCS was also confirmed by high-performance liquid chromatography.
\end{abstract}

Keywords Actinobacteria $\cdot$ Streptomyces $\cdot$ Amylase $\cdot$ Glucose isomerase $\cdot$ High fructose corn syrup

\section{Introduction}

High fructose corn syrups (HFCS) in the past half century have gained remarkable attention as a sweetener for food and beverage industry. This liquid sweetener was developed in the $1960 \mathrm{~s}$ as a partial replacement to sucrose which suffered production shortages and price hikes after Cuban revolution [1]. HFCS is an equilibrium mixture of glucose and fructose which has sweetening ability comparable with sucrose [2]. Fructose in HFCS is 1.3 times sweeter than sucrose and 1.7 times sweeter than glucose. Thus, HFCS possesses a higher sweetening capacity. This sweetener possesses a high commercial value, and its annual production is estimated to be 10 million tons [1].

Fructose is twice as sweet as sucrose, and glucose imparts $70-75 \%$ sweetening as that of sucrose [3]. HFCS is chiefly produced from non-sweet sources like starch or cellulose which makes it cheaper than sucrose [4]. Apart from this, HFCS is stable and does not pose the problem of crystallization. Its commercial manufacturing began from 1970 s opening a new frontier in the sweetening market.

The industrial production of HFCS requires two important stages. In initial step, amylase is employed for saccharification of non-sweet starch to monomeric glucose units followed by its isomerization into fructose using glucose isomerase [5]. Usually two variants, HFCS-42 (42\% fructose) and HFCS-55 (55\% fructose) are available commercially [6]. The concentration of fructose in HFCS can be enriched to $90 \%$, but industrially HFCS-55 is chiefly used as sweetener in cold drinks, ice cream and yogurts. HFCS-42 finds its usage in confectionary and beverage industries [7].

Sheetal Bhasin, sheetalrbhasin@gmail.com | 'Department of Biosciences, Maharaja Ranjit Singh College of Professional Sciences, Indore, M.P., India. ${ }^{2}$ School of Life Sciences, Devi Ahilya Vishwavidyalaya, Indore, M.P., India. 
The HFCS is produced globally, $41 \%$ of which is consumed by the beverage industries of USA. In India, sugarcane-derived sugar is still the chief sweetener. These sweeteners need to be replaced with HFCS as it has numerous benefits. HFCS is useful for diabetic patients also. It has low calorific value, and moreover insulin is not required for absorption of fructose in blood. HFCS can be transported easily in its liquid form as there is no problem of crystallization [8]. Due to its medical advantages, HFCS production on large scale from cheap starchy source is in demand. Owing to the great abundance of starchy by-products in India and high international market demand of HFCS, we can establish plants here to earn foreign exchange which will increase our share in international trade.

In this study, potential GI- and amylase-producing actinobacteria have been screened and identified using morphological and molecular techniques. The 16S rRNA sequence of both the selected strains Streptomyces sp. TSA. $\mathrm{KP}(\mathrm{KP})$ and Streptomyces sp. TSA.Dm $1(\mathrm{Dm} 1)$ has been submitted to $\mathrm{NCBI}$, and this is the first report on utilizing these organisms for the production of $\mathrm{Gl}$ and amylase, respectively. Different production media were checked for maximum production of $\mathrm{Gl}$ and amylase, and properties of both the enzymes were studied. The enzymes produced were later used for the production of HFCS.

\section{Materials and methods}

All the chemicals used were purchased from HiMedia and Merck.

\subsection{Isolation of actinobacteria from soil}

The soil samples from forty different regions of Madhya Pradesh, India, were collected in sterile polybags. Soil samples were procured from 5 to $6 \mathrm{~cm}$ depth using a spatula. The isolation was carried out using actinomycetes isolation agar and Bennett's agar medium. Selective isolation of actinobacteria was promoted by incorporating amphotericin B $(20 \mu \mathrm{g} / \mathrm{ml})$, ampicillin $(3 \mu \mathrm{g} / \mathrm{ml})$ and erythromycin $(1 \mu \mathrm{g} /$ $\mathrm{ml})$. Morphologically diverse actinobacteria were procured and preserved on Bennett's agar slants for further studies.

\subsection{Screening for production of glucose isomerase (GI)}

The actinobacterial isolates were spot inoculated on $\mathrm{X}+\mathrm{P}-$ (xylose $1 \%, \mathrm{KNO}_{3} 0.2 \%, \mathrm{~K}_{2} \mathrm{HPO}_{4} 0.2 \%, \mathrm{NaCl} 0.2 \%$, $\mathrm{MgSO}_{4} 0.05 \%, \mathrm{FeSO}_{4} 0.01 \%, \mathrm{CaCO}_{3} 0.02 \%$ and $\mathrm{pH} 8.0 \pm 0.2$ ), $\mathrm{X}+\mathrm{P}+$ and wheat bran medium for primary screening [9] and incubated at $30^{\circ} \mathrm{C}$ for 7 days. The $\mathrm{X}+\mathrm{P}+$ media is comprised peptone $(0.03 \% \mathrm{w} / \mathrm{v})$ additionally along with all the other components of $\mathrm{X}+\mathrm{P}-[9]$. The plates were observed regularly for growth. The isolates exhibiting early lavish growth on $\mathrm{X}+\mathrm{P}$ - media were considered good producers of $\mathrm{Gl}$. Gl is considered to be intracellular in majority of the cases; in this study, we intend to focus on extracellular Gl production in order to reduce the product recovery cost. Therefore, in secondary screening we performed a comparative study of extracellular and intracellular $\mathrm{Gl}$ production.

The submerged fermentation process was carried out in modified Bennett's medium (xylose $1 \%$, tryptone $0.1 \%$, yeast extract $0.1 \%$, beef extract $0.1 \%$ and $\mathrm{pH} 8.0 \pm 0.2$ ). Top ten promising $\mathrm{Gl}$ producing isolates were inoculated using 8-mm culture disk of $96-\mathrm{h}$-old culture of isolates. The inoculated broth was incubated in a rotatory shaker (REMI $\mathrm{CIS}-24 \mathrm{BL}$ ) at $30^{\circ} \mathrm{C}$ at $100 \mathrm{rpm}$. Fermentation process was terminated after $96 \mathrm{~h}$, and the fermented broth was centrifuged at $5600 \times g$ for $10 \mathrm{~min}$. The supernatant was used as crude extracellular enzyme extract.

To estimate the production of intracellular Gl, the pellet obtained after centrifugation in the above procedure was washed thrice using distilled water ( $\mathrm{pH} 7.0)$. Further, it was suspended in $0.05 \mathrm{M}$ sodium phosphate buffer $(\mathrm{pH}$ 7.0) containing $0.1 \%$ cetyl trimethyl ammonium bromide (CTAB). This mixture was incubated in shaking condition at $37^{\circ} \mathrm{C}$ for $24 \mathrm{~h}$ at $100 \mathrm{rpm}$. Later, it was centrifuged at $5600 \times g$ for $5 \mathrm{~min}$ and the supernatant was used as crude intracellular enzyme [11].

\subsection{Screening for production of amylase}

The isolates were tested for synthesis of amylase using plate assay method. The isolates were spot inoculated on Bennett's medium containing $1 \%$ starch and incubated at $30{ }^{\circ} \mathrm{C}$ for 4 days. Plates were flooded with iodine solution to observe the zone of hydrolysis [10].

The isolates exhibiting large zone of clearances in the plate assay method were analyzed further for amylase production by submerged fermentation process. The potential isolates were inoculated into Bennett's medium containing $1 \%$ starch and incubated at $30^{\circ} \mathrm{C}$ for 4 days at $100 \mathrm{rpm}$. The fermented broth was harvested after incubation and assayed for amylase production.

\subsection{Selection of suitable production medium for GI}

Production of $\mathrm{Gl}$ is greatly influenced by the nutrient combination present in the medium; in order to enhance the $\mathrm{Gl}$ production, different media were tested. Gl was produced in Bennett's medium, modified Bennett's medium, Lobanok medium [12], Srih Belghith medium [13], Hasal medium [14] and $\mathrm{X}+\mathrm{P}+$ [9] production media by submerged fermentation process for selection of suitable 
production medium. The Gl produced was estimated by the method suggested by Chen et al. [18].

\subsection{Selection of suitable production medium for amylase}

Top three amylase producers were subjected to submerged fermentation process in four different production media: Haritha's medium [15], Acharyabhatta medium [16], Raghunathan medium [17] and Bennett's medium for determining the most suitable production medium. The amylase produced was estimated by the method suggested by Raghunathan and Padhmadas [17].

\subsection{GI assay}

The $\mathrm{Gl}$ was assayed by preparing a reaction mixture containing $500 \mu \mathrm{l}$ of $0.5 \mathrm{M}$ phosphate buffer, $200 \mu \mathrm{l}$ of $1 \mathrm{M}$ glucose, $100 \mu \mathrm{l}$ of $0.1 \mathrm{M} \mathrm{MgSO}_{4}, 100 \mu \mathrm{l}$ of $0.01 \mathrm{M} \mathrm{CoCl}_{2}$ and $200 \mu \mathrm{l}$ of crude enzyme. The volume was made up to $2 \mathrm{ml}$, and the reaction was carried out at $70^{\circ} \mathrm{C}$ for $1 \mathrm{~h}$. The reaction was stopped using $2 \mathrm{ml} 0.5 \mathrm{M}$ perchloric acid [18].

To estimate the amount of fructose formed, $0.05 \mathrm{ml}$ of above aliquot was taken to which $0.95 \mathrm{ml} \mathrm{D} / \mathrm{W}$ was added followed by $200 \mu \mathrm{l}$ of $1.5 \%$ cysteine hydrochloride, $6 \mathrm{ml}$ $70 \% \mathrm{H}_{2} \mathrm{SO}_{4}$ and $200 \mu \mathrm{l}$ of $0.12 \%$ alcoholic carbazole. The purple color thus formed was read spectrophotometrically at $560 \mathrm{~nm}$ [19], and the concentration was determined using fructose calibration curve. One unit of glucose isomerase activity was defined as the amount of enzyme required to produce $1 \mu \mathrm{mol}$ of fructose per minute, under assay conditions.

\subsection{Amylase assay}

The amylase was assayed by adding $0.2 \mathrm{ml}$ of enzyme extract to $0.5 \mathrm{ml} 1 \%$ starch solution. The reaction mixture was incubated at $37^{\circ} \mathrm{C}$ for $30 \mathrm{~min}$. The reaction was stopped by adding $1 \mathrm{ml}$ DNS to the reaction mixture. The reaction mixture was kept in boiling water bath for $10 \mathrm{~min}$, and the total volume was made to $5 \mathrm{ml}$. The absorbance was read at $540 \mathrm{~nm}$ using UV-visible spectrophotometer (ThermoSpectronic).

One unit of amylase enzyme activity was defined as the amount of enzyme required to liberate $1 \mu \mathrm{mol}$ of glucose per min under the assay conditions [17].

\subsection{Identification of GI-producing isolate KP and amylase-producing isolate Dm1}

The identification of the $\mathrm{Gl}$ - and amylase-producing actinobacteria was carried out in two steps, i.e., morphological analysis and molecular characterization.

\subsubsection{Morphological analysis of isolate KP and Dm1}

The selected $\mathrm{Gl}$ and amylase producers were analyzed for their morphological details by studying spore arrangement pattern. Preliminary morphological analysis of selected isolates was performed by slide culture technique. Detailed morphological analysis was done by scanning electron microscopy at $18000 \mathrm{X}$ and $19000 \mathrm{X}$.

\subsubsection{Molecular characterization of isolate KP and Dm1}

Molecular characterization of isolate $\mathrm{KP}$ and $\mathrm{Dm} 1$ was performed by $16 \mathrm{~S}$ rRNA sequencing. The chromosomal DNA of both actinobacteria was isolated using the DNA isolation spin column kit (HiMedia). The 16S rRNA was amplified using 27F (5'-GAGTTTGATCMTGGCTCAG-3') as the forward primer and 1492R (5'-TACGGYTACCTT GTTACGACTT-3') as the reverse primer [20]. The PCR product was purified using Exonuclease 1-Shrimp Alkaline phosphatase (Exo-Sap), and then the amplicons were sequenced through Sanger's method using a $A B I$ $3500 \times \mathrm{L}$ genetic analyzer (Life Technologies, USA). This process of identification of actinobacterial species was carried out at National Collection of Industrial Microorganisms (NCIM), NCL-CSIR, Pune, India. The sequence obtained was matched with the GenBank database using BLASTN algorithm to reveal the closest match of $16 \mathrm{~S}$ rRNA from the known species. Phylogenetic tree was constructed using sequence of our isolate and the first 25 closely related sequences picked up from BLAST result using MEGA-X program.

\subsection{Determination of optimum fermentation period for GI production and study of growth pattern of isolate KP}

This study was done by inoculating 8-mm culture disk (from 9-h-old culture of isolate KP) into ten flasks containing modified Bennett's medium. Submerged fermentation process was carried out at $30^{\circ} \mathrm{C}$ in shaking condition at $100 \mathrm{rpm}$. Daily, a flask was drawn, its contents were centrifuged at $5600 \times g$ for $10 \mathrm{~min}$, and the supernatant was assayed for Gl activity. The growth pattern of the isolate was studied by estimating the increase in biomass. During the time course of 10 days, biomass was estimated by measuring the dry weight of the growth obtained at an interval of $24 \mathrm{~h}$. The pellet was washed with distilled water and was filtered through preweighed Whatman's filter paper and dried overnight at $45^{\circ} \mathrm{C}$. After complete drying, the filter paper was weighed again and biomass was recorded. 


\subsection{Determination of optimum fermentation period for amylase production and growth pattern of isolate Dm1}

To determine the optimum incubation period for maximum amylase production, 8-mm culture disk from 96-hold culture of isolate Dm1 was inoculated into ten flasks containing Haritha's medium. Submerged fermentation was performed at $30^{\circ} \mathrm{C}$ at $100 \mathrm{rpm}$. Each day a flask was drawn, the fermented broth was centrifuged at $5600 \times g$ for $10 \mathrm{~min}$ and the supernatant was assayed for amylase. Growth was estimated by analyzing the dry weight [17]. The pellet was washed with distilled water and was filtered through preweighed Whatman's filter paper and dried for overnight at $45^{\circ} \mathrm{C}$. The filter paper was weighed again after complete drying, and the biomass was recorded.

\subsection{Effect of temperature on GI and amylase activity}

The effect of temperature on the activity of both $\mathrm{Gl}$ and amylase was investigated. For determination of optimum temperature for $\mathrm{Gl}$ activity, the isomerization process was carried out at different temperatures, i.e., $50{ }^{\circ} \mathrm{C}, 60^{\circ} \mathrm{C}$, $70^{\circ} \mathrm{C}, 80^{\circ} \mathrm{C}, 90^{\circ} \mathrm{C}$ and $100^{\circ} \mathrm{C}$. Similarly, an optimum temperature for amylase activity was determined by carrying out the starch hydrolysis at different temperatures $15^{\circ} \mathrm{C}$, $22^{\circ} \mathrm{C}, 30^{\circ} \mathrm{C}, 37^{\circ} \mathrm{C}, 42^{\circ} \mathrm{C}$ and $55^{\circ} \mathrm{C}$.

\subsection{Effect of pH on GI and amylase activity}

The effect of $\mathrm{pH}$ on $\mathrm{Gl}$ and amylase activity was determined by carrying out isomerization and hydrolysis reactions, respectively, at different $\mathrm{pH}$ ranges from 4 to 12 . Different buffers were used for maintaining constant $\mathrm{pH}$ of the reaction system. For $\mathrm{pH} 4$ and 5 , acetate buffer was used, phosphate buffer for $\mathrm{pH} 6$ and 7, tris buffer for $\mathrm{pH} 8$ and 9, and glycine buffer for $\mathrm{pH} 10,11$ and 12 .

\subsection{Kinetic properties of GI and amylase}

Kinetic properties of $\mathrm{Gl}$ and amylase were determined using Lineweaver-Burk plot. Glucose was used as the substrate for studying kinetic properties of $\mathrm{Gl}$, and similarly starch was employed as the substrate for analyzing kinetic properties of amylase. Both the substrates used in this study were introduced in the concentration ranging from 0.1 to $2.0 \mathrm{M}$. The $\mathrm{pH}$ for both $\mathrm{Gl}$ and amylase for kinetic studies was 7.0 , and temperature was kept $70^{\circ} \mathrm{C}$ and $37^{\circ} \mathrm{C}$, respectively.

\subsection{Production of HFCS}

Corn starch was utilized as the initial polysaccharide, and the process of HFCS production was done in two steps. The initial process involved hydrolysis of corn starch into glucose subunits for which the crude amylase from isolate $\mathrm{Dm} 1$ was utilized. The corn starch $(1 \% \mathrm{w} / \mathrm{v})$ was dissolved in $0.5 \mathrm{M}$ phosphate buffer $(\mathrm{pH} 7.0)$ to which crude enzyme was added and incubated at $37^{\circ} \mathrm{C}$. The mixture was tested at different time intervals for decrease in level of starch which was estimated using starch iodine complex method. The amount of glucose units generated was estimated using the DNS method. This step was followed by isomerization of glucose units into fructose which was done by adding crude $\mathrm{Gl}$ from isolate $\mathrm{KP}$ to the above mixture. Isomerization was carried out at $70^{\circ} \mathrm{C}$. The reaction mixture was tested for the production of fructose until no rise in isomerization was observed. The amount of fructose produced was estimated using the cysteine-carbazole method.

\subsection{End product analysis using HPLC}

The HFCS produced using amylase and GI from Streptomyces $s p$. was analyzed for the presence of sugars. This analysis was done using HPLC, Waters, USA, equipped with Sugar-Pak column of $6.5 \times 300 \mathrm{~mm}, 515$ HPLC pump and $\mathrm{RI}$ detector 2414 . The injection volume was $20 \mu \mathrm{l}$, and HPLC-grade water was used as mobile phase with flow rate of $0.3 \mathrm{ml} / \mathrm{min}$. The HFCS produced was filtered using PVDF syringe equipped with a $0.45 \mu \mathrm{m}$ filter, and the filtrate was injected ( $20 \mu \mathrm{l})$ into the HPLC system using Hamilton's syringe. The analysis was carried out using Empower 2 software.

\section{Results and discussion}

\subsection{Isolation of actinobacteria from soil}

Soil inhabits diverse groups of microbiota which can serve as a resource for the isolation of microorganisms with desired properties. Actinobacteria cover a major portion of microbial soil population and are considered valuable due to their ability to produce numerous enzymes for mineralization and diverse secondary metabolites. In our present study, soil samples gathered from 40 locations yielded 120 morphologically different actinobacterial isolates which were preserved on Bennett's agar slants. The sampling area included soil from garden, cultivated land, compost pits, rhizospheric soil, wastelands and dump yards. Actinobacteria were found to be present in all the samples collected. From the 12 garden soil samples, 43 


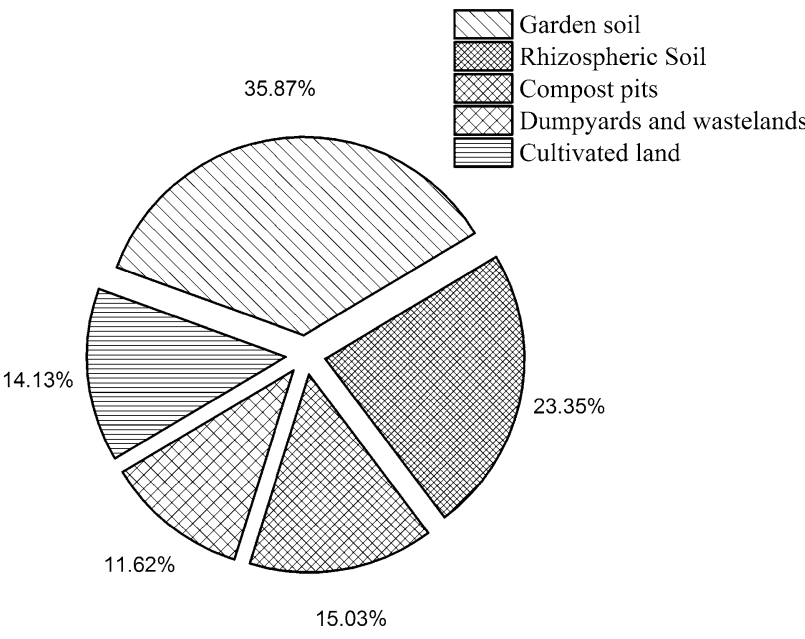

Fig. 1 Isolation of actinobacteria from different soil samples

actinobacterial cultures were isolated and rhizospheric soil yielded 28 actinobacterial isolates followed by that of compost pits ( 18 isolates), cultivated land (17 isolates) and wastelands (14 isolates). The presence of organic matter and other nutritional sources might be the reason for this observation. The details of the isolation are mentioned in Fig. 1.

\subsection{Screening for production of glucose isomerase} (GI)

All actinobacterial isolates were checked for their ability to produce $\mathrm{Gl}$. Results exhibited that among 120 isolates, only 25 exhibited Gl activity which accounts to $18 \%$ of the total. The ability of glucose isomerase to convert xylose into xylulose was utilized for the screening purpose. The microbes cannot utilize xylose directly as the source of carbon but instead convert it into xylulose for consumption. $\mathrm{X}+\mathrm{P}-$ medium comprises solely of xylose as the source of carbon allowing the selective growth and survival of $\mathrm{Gl}$ producing isolates. The isolates exhibiting early lavish growth on this medium were considered good producers of $\mathrm{Gl}$. On the contrary, $\mathrm{X}+\mathrm{P}+$ promotes better growth as it contains peptone, whereas wheat bran facilitates early sporulation as it is rich in growth factors. Wheat bran and $\mathrm{X}+\mathrm{P}+$ media were used as positive controls. As a result of primary screening, 4 isolates were selected for secondary screening. Glucose isomerase has been reported in majority of cases as an intracellular enzyme. The processing and isolation of such enzymes make it expensive due to which extracellular GI has been of particular interest. In our investigation, we analyzed both intracellular and extracellular production and the isolates $\mathrm{BD} 1, \mathrm{BD} 2, \mathrm{KP}$ and $\mathrm{S} 3$ were found to be the best GI producers. These selected isolates produced extracellular as well as intracellular Gl (Table 1).
Table 1 Comparative analysis of extracellular and intracellular Gl production exhibited by different isolates in modified Bennett's medium

\begin{tabular}{lll}
\hline Isolate code & \multicolumn{2}{c}{ Modified Bennett's medium } \\
\cline { 2 - 3 } & Extracellular & Intracellular \\
\hline RK1 & $2.40 \pm 0.38$ & $1.36 \pm 0.62$ \\
BD1 & $3.36 \pm 0.63$ & $1.71 \pm 0.45$ \\
BD2 & $3.26 \pm 0.51$ & $0.58 \pm 0.28$ \\
KP & $4.72 \pm 0.78$ & $1.93 \pm 0.43$ \\
HO6 & $2.94 \pm 0.33$ & $1.06 \pm 0.26$ \\
OM2 & $1.33 \pm 0.38$ & $0.18 \pm 0.09$ \\
PS2 & $2.29 \pm 0.47$ & $0.85 \pm 0.31$ \\
CK & $2.67 \pm 0.73$ & $1.12 \pm 0.53$ \\
Db1 & $1.49 \pm 0.52$ & $0.64 \pm 0.24$ \\
S3 & $4.27 \pm 1.03$ & $0.90 \pm 0.37$ \\
\hline
\end{tabular}

The values refer to enzyme activity in $\mathrm{EU} / \mathrm{ml}($ mean $\pm \mathrm{SD}, n=3)$

The isolate KP exhibited the highest extracellular enzyme production in modified Bennett's medium. Majority of isolates exhibited more extracellular enzyme accumulation as compared to intracellular. Here we focus on the production of extracellular Gl as they are generally stable and easier to purify which reduces the cost of production [21]. In order to achieve maximum recovery of enzyme, both extracellular and intracellular enzymes must be extracted, but at industrial scale it becomes expensive and time consuming. Recovery of intracellular enzymes requires disruption of cell biomass using chemicals or sonicator which increases the overall cost of enzyme production. Thus, extracellular enzymes are of major preference at industrial levels.

\subsection{Screening for production of amylase}

From the gathered lot, $36 \%$ (43 out of 120 ) isolates exhibited amylase production. Amylase being an inducible enzyme is synthesized by the isolate to utilize the starch incorporated within the medium. The potential of isolate to produce amylase was analyzed by the plate assay method by measuring the zone of clearance around its colony on starch agar plate. The zone diameter of amylase producing isolates ranged from $3 \mathrm{~mm}$ to $32 \mathrm{~mm}$ (Fig. 2).

The quantitative analysis of amylase production using submerged fermentation process was carried out using eight potential actinobacterial isolates selected from the plate assay method. The potential amylase producing isolates were found to be Dm1, B and S9 which exhibited high amylase production in the submerged fermentation process. The results are shown in Fig. 3. 


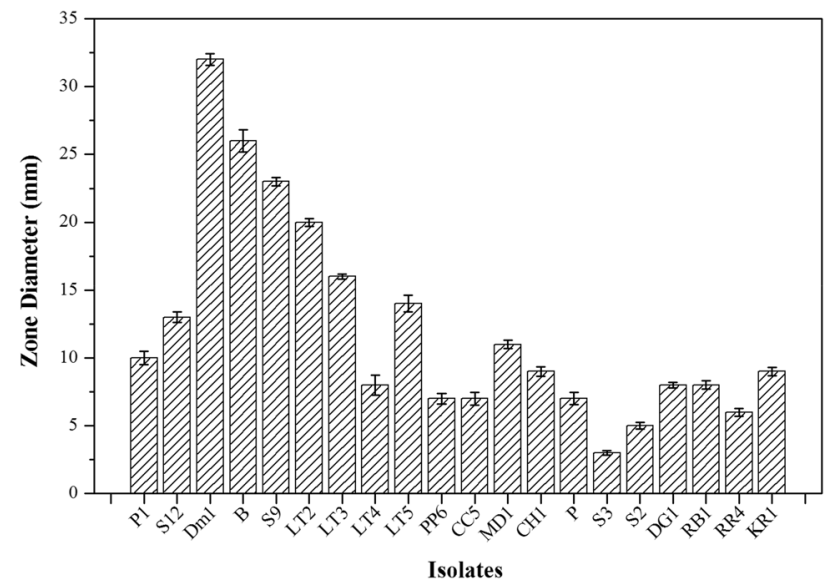

Fig. 2 Comparative analysis of amylase production by different isolates

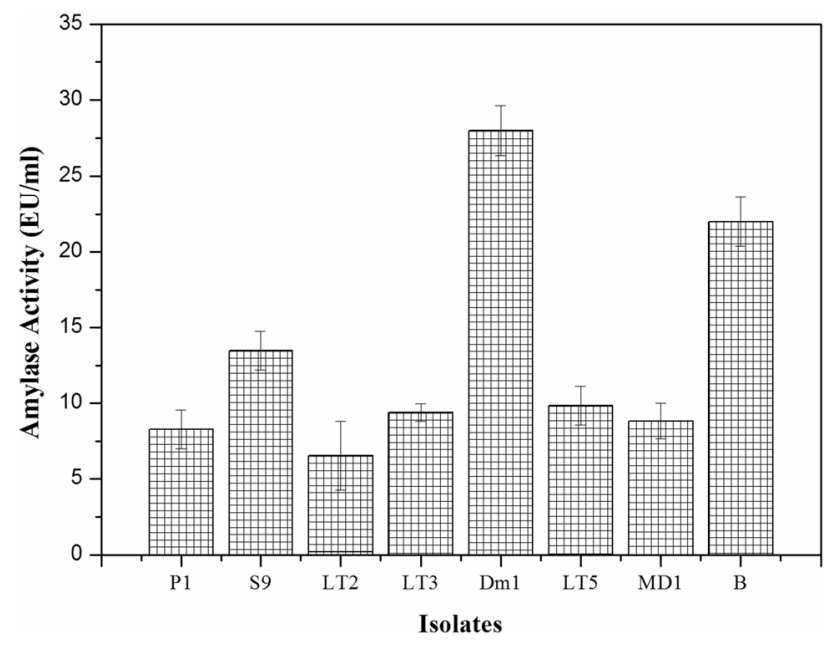

Fig. 3 Submerged fermentation process for quantitative analysis of amylase

\subsection{Selection of suitable production medium for GI}

The growth and production of enzymes and metabolites of actinobacteria depends on the presence of carbon and nitrogen sources in any medium. We analyzed the $\mathrm{Gl}$ production by top 4 isolates in different medium combinations.

Among the 4 isolates, KP produced maximum amount of $\mathrm{Gl}$. The modified Bennett's medium proved to be the best for Gl production for actinobacterial isolate KP followed by Lobanok's, and Srih Belghith medium (Fig. 4). In the modified Bennett's medium, glucose has been replaced with xylose which proves that xylose acts as an inducer for $\mathrm{Gl}$ production as majority of isolates exhibited high $\mathrm{Gl}$ production in this medium. On the contrary, isolate BD2 exhibited good GI production in Bennett's medium

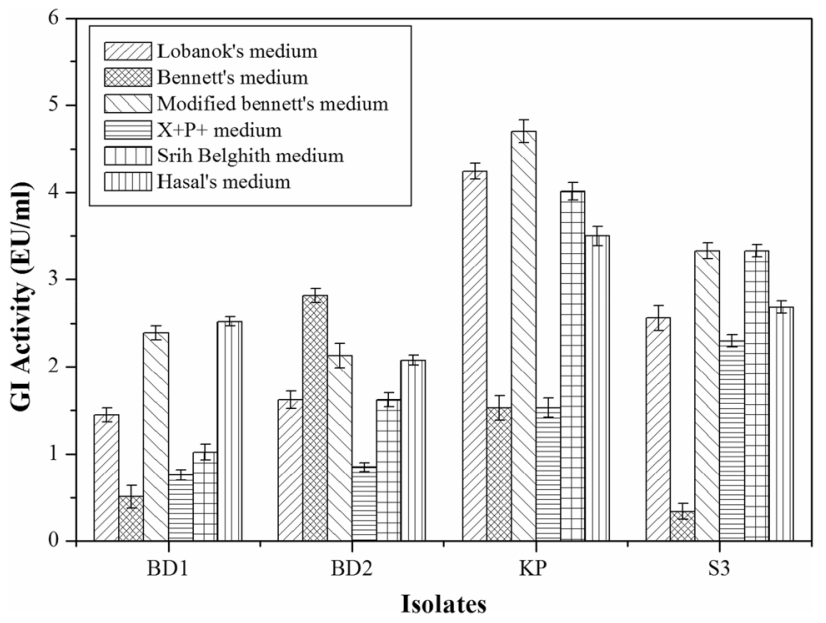

Fig. $4 \mathrm{Gl}$ production in different media

containing glucose as the carbon source. The Gl production by isolate BD2 decreased in the presence of xylose, which shows that BD2 utilizes glucose as an inducer for $\mathrm{Gl}$ production. Xylose is known to induce $\mathrm{Gl}$ in numerous actinobacteria [1], but there are reports on GI production without xylose as in Actinoplanes [22]. Manhas and Bala [21] also reported high $\mathrm{Gl}$ production in medium containing xylose as the carbon source.

\subsection{Selection of suitable production medium for amylase}

The selected amylase producers were introduced into different production media. Isolate Dm 1 exhibited the highest amylase yield of $88.31 \pm 1.31 \mathrm{EU} / \mathrm{ml}$ in Haritha's medium followed by isolate S9 $(67 \pm 1.41)$ and B $(61.1 \pm 1.39)$. Among different production media, Haritha's medium proved to be the most suitable for the production of amylase (Fig. 5). The isolate Dm1 and Haritha's medium promoted the highest amylase production.

\subsection{Identification of GI-producing isolate KP and amylase-producing isolate $\mathrm{Dm} 1$}

\subsubsection{Morphological analysis of isolate KP and Dm1}

The isolate KP grows well on Bennett's agar medium at $30{ }^{\circ} \mathrm{C} \mathrm{pH} 7$ as powdery colonies with gray-colored aerial spore mass, grayish color colony reverse and no pigmentation. Isolate $\mathrm{Dm} 1$ also grows on the same medium and with the same physiological parameters as greenish ivorycolored colonies with pale yellow colony reverse and no pigmentation. The spore ornamentation was studied by performing slide culture technique. The aerial mycelia appeared dark in color on thin slender substrate mycelia 


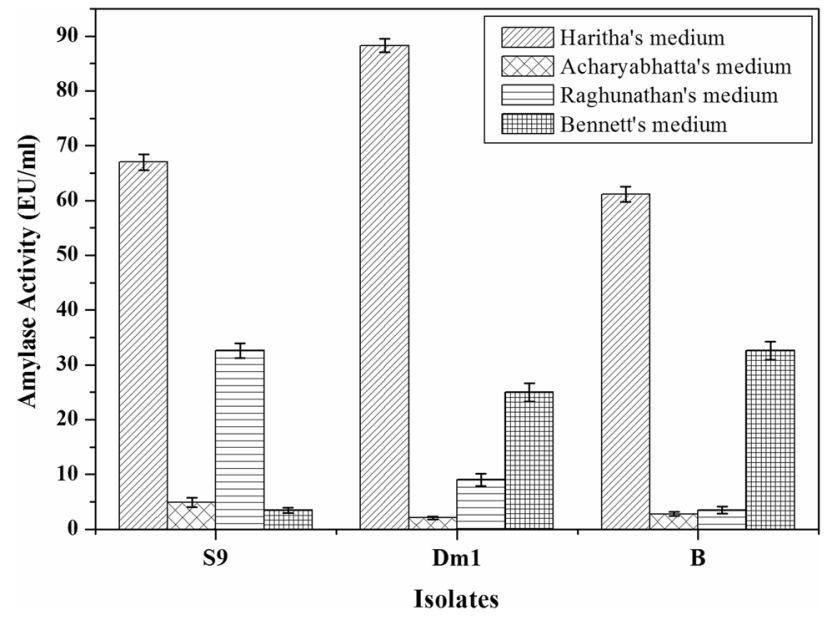

Fig. 5 Amylase production in different media

in phase contrast microscope. The spores could be seen as beads in curved arrangement. The scanning electron microscopic pictures revealed spores as small rod-shaped structures arranged in either curved or in spiral chains. The surface of spores appeared rough and wavy for isolate KP (Fig. 6a). The spore chains of Dm1 appeared spiral and the spore surfaces were rough (Fig. 6b). The spore ornamentation is indicative of the isolates belonging to Streptomyces sp.

\subsubsection{Molecular characterization of isolate KP and Dm1}

The complete $16 \mathrm{~S}$ rRNA sequence of isolates KP (1328 bp) and Dm1 (1214 bp) was obtained. These isolates were identified as Streptomyces sp. The sequences were submitted to NCBI. The GI producer is registered in GenBank as Streptomyces sp. strain T.S.A.KP accession number MN911386. This strain was identified as Streptomyces enissocaesilis on performing BLASTn. This is the first report on S. enissocaesilis for the production of $\mathrm{Gl}$ to the best of our knowledge. Researchers have reported its potential for the production of antimicrobial used in medical as well as agricultural field, but there are no findings available for $\mathrm{Gl}$ production from it [23, 24]. The amylase producer Streptomyces sp. strain TSA.Dm1 is registered in GenBank with accession number MN923073. This isolate was found closely related to Streptomyces sampsonii. The phylogenetic tree was constructed using MEGA X program for both the isolates Streptomyces sp. strain T.S.A.KP and Streptomyces sp. strain TSA.Dm1 separately. The tree was constructed with 26 sequences; i.e. our isolate $16 \mathrm{~S}$ rRNA sequence and first 25 closely related sequences received from BLAST result. The results revealed query coverage of 99\% in BLAST with the score 2438 showing $100 \%$ identity with Streptomyces enissocaesilis strain NRRL B-16365. The
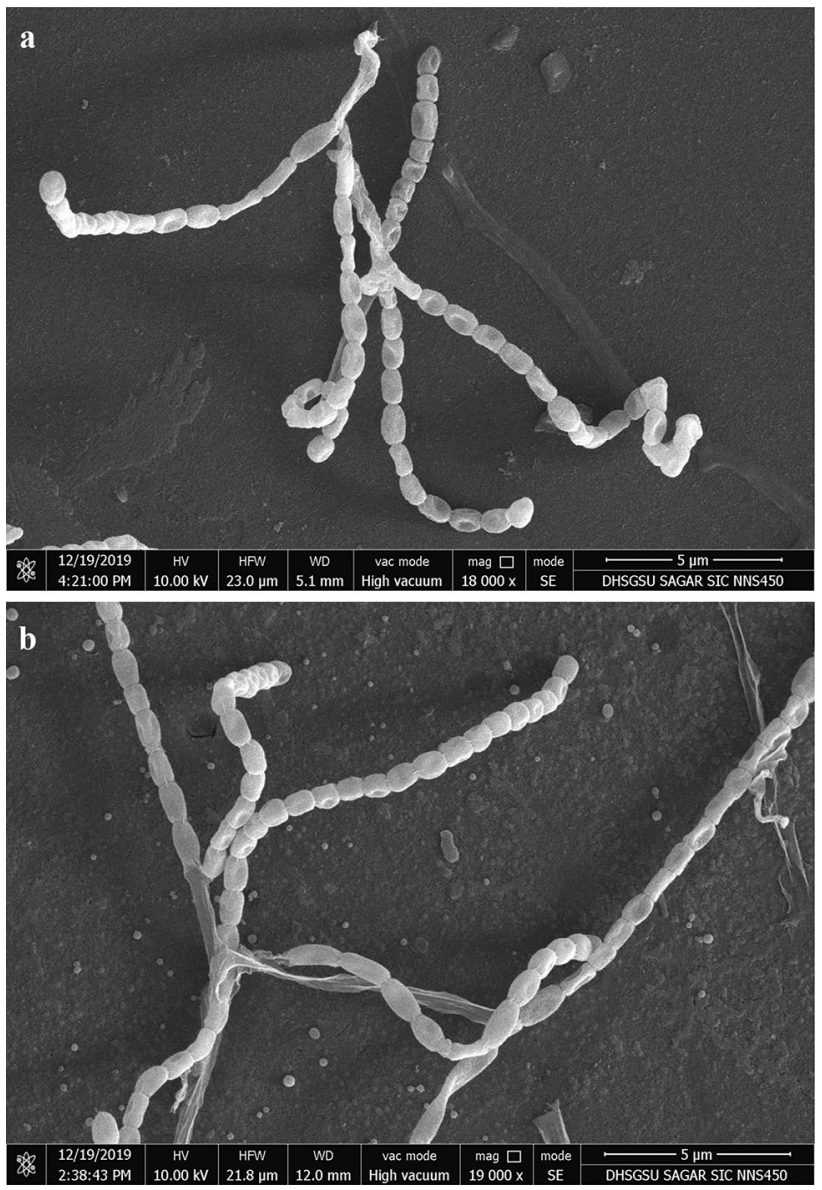

Fig. 6 a Spore chain arrangement of isolate KP under scanning electron microscope. $\mathbf{b}$ Spore chain arrangement of isolate $\mathrm{Dm} 1$ under scanning electron microscope

phylogenetic tree in Fig. 7 also explains the placement of our newly reported culture closest to Streptomyces enissocaesilis. BLAST results for Streptomyces sp. strain TSA. Dm 1 exhibited $100 \%$ query coverage with 2377 score and 99.17\% identity with Streptomyces sampsonii strain ATCC 25495. Tree constructed using these results is depicted in Fig. 8 support that our isolate is clustered in Streptomyces group.

\subsection{Optimum fermentation period for GI production and study of growth pattern of isolate KP}

The highest enzyme production was observed on the 5th day $(120 \mathrm{~h})$ from incubation. The study also showed that the production of enzyme increases with respect to the growth of the isolate and attains maxima during the end of logarithmic phase. It is evident in the present study that the enzyme production is taking place in log phase which proves that $\mathrm{Gl}$ is important for the growth of organism [18, 
Fig. 7 Phylogenetic tree of the $16 \mathrm{~S}$ rRNA gene sequence of Streptomyces sp. TSA.KP and other closely related gene sequences

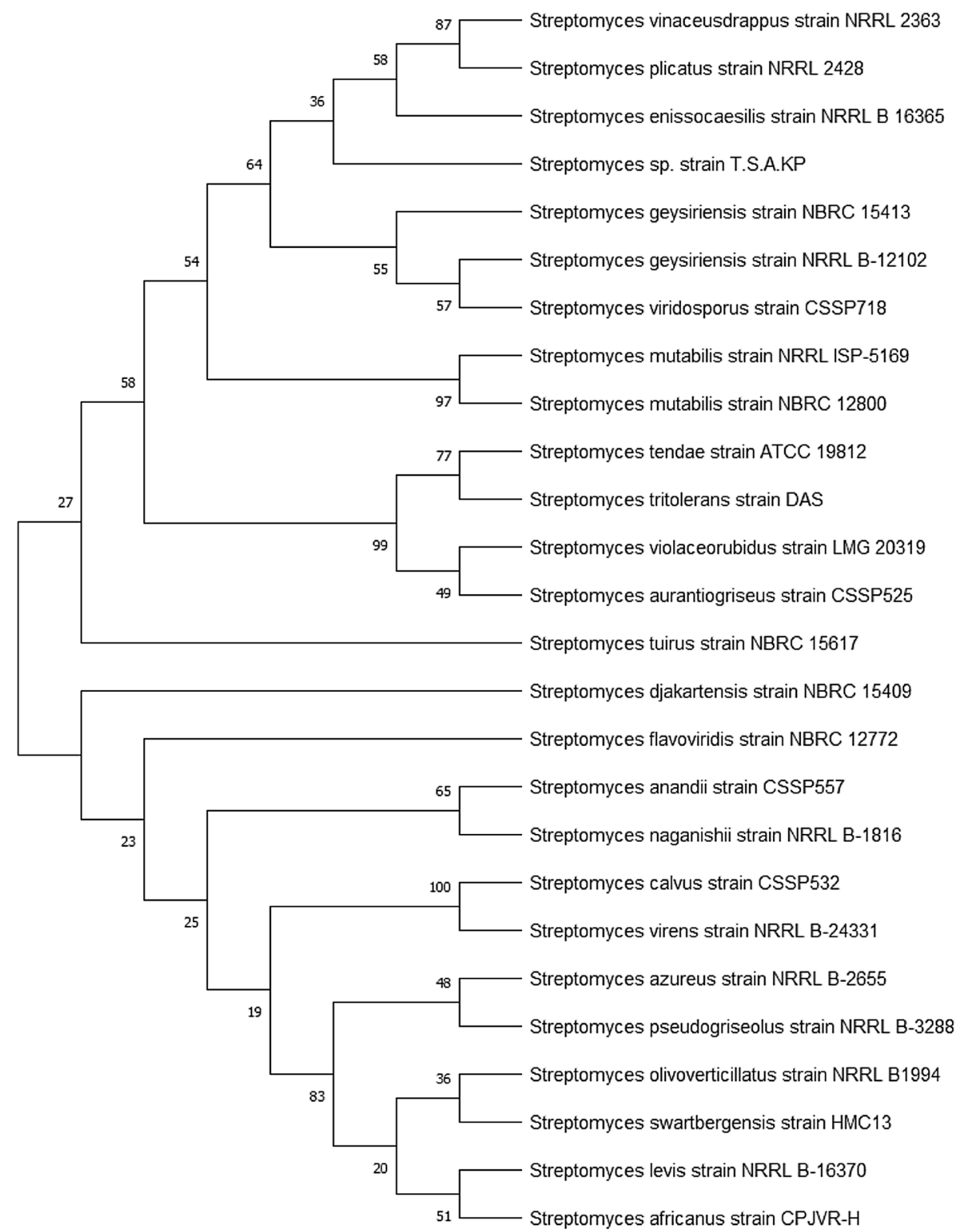

25]. Different researchers have reported maximum enzyme accumulation between 36 and $96 \mathrm{~h}$ [9]. Dhungel et al. [25] obtained maximum production of Gl after $96 \mathrm{~h}$ (Fig. 9a), whereas Chen et al. [18] achieved the same in $72 \mathrm{~h}$.

\subsection{Optimum fermentation period for amylase production and growth pattern of isolate Dm1}

The considerable amylase production was observed after $24 \mathrm{~h}$ of fermentation process which reached maximum on $96 \mathrm{~h}$ (4th day) from incubation (Fig. 9b). The current study establishes that amylase is an important enzyme for the growth of the organism as it is synthesized during the log phase of an organism. Salahuddin et al. [26] also noticed maximum production in $96 \mathrm{~h}$ from thermophilic strains of actinobacteria. Some researchers reported reduction in enzyme activity on 4th day in case of Rhodococcus sp. [17], whereas Selvan et al. [27] found the highest enzyme accumulation on 7th day from marine actinobacteria.

\subsection{Effect of temperature on $\mathrm{Gl}$ and amylase activity}

The optimum temperature for $\mathrm{Gl}$ activity was found to be $70^{\circ} \mathrm{C}$, and that of amylase activity was $37^{\circ} \mathrm{C}$. A maximum Gl activity of $4.78 \pm 0.13 \mathrm{EU} / \mathrm{ml}$ was obtained at $70^{\circ} \mathrm{C}$ (Fig. 10a). Earlier reports also suggest that isomerization requires a higher temperature range. The isomerization temperature of commercially available $\mathrm{Gl}$ is $55-60{ }^{\circ} \mathrm{C}$. Gl that can carry out isomerization at higher temperatures than the currently available ones enhances the possibility of production of HFCS with higher D-fructose content 
Fig. 8 Phylogenetic tree of the $16 \mathrm{~S}$ rRNA gene sequence of Streptomyces sp. TSA.Dm1 and other closely related gene sequences

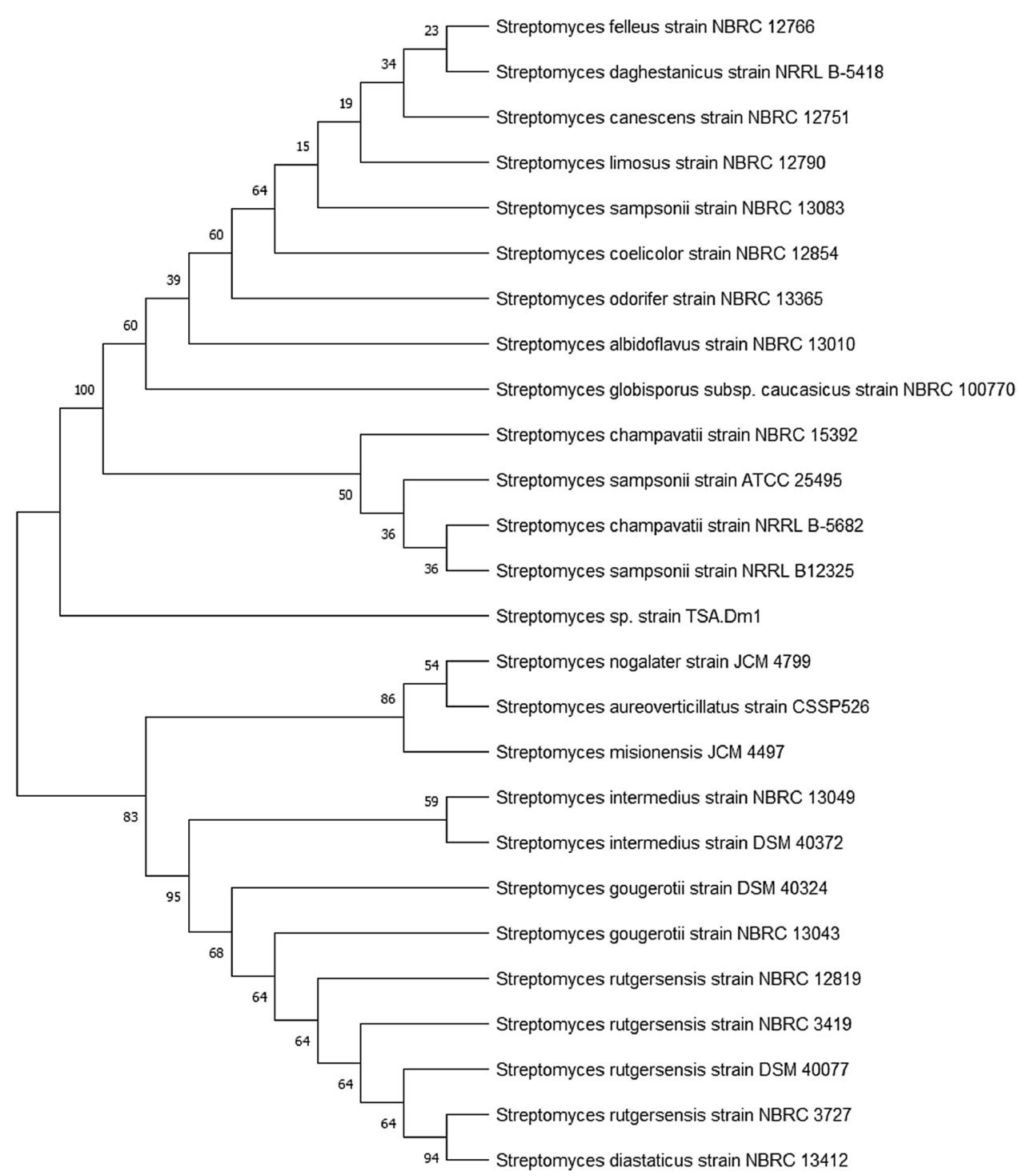

[28]. For industrial use, Gl active at higher temperature is advantageous as it helps in the reduction of viscosity of the substrate.

In the present study, the maximum amylase activity of $88.24 \pm 1.32 \mathrm{EU} / \mathrm{ml}$ was observed at $37^{\circ} \mathrm{C}$ (Fig. 10b). Amylases working at different temperatures have been reported. Kaneko et al. [29] reported Streptomyces sp. synthesizing amylase that was able to carry out maximum activity at $40^{\circ} \mathrm{C}$. Yassien and Asfour [30] reported amylase from Streptomyces clavifer exhibiting maximum activity at the range of $40-50^{\circ} \mathrm{C}$. Industrially enzyme working at a moderate temperature of $35-40^{\circ} \mathrm{C}$ is advantageous as this temperature range can be economically maintained [31].

\subsection{Effect of pH on GI and amylase activity}

The optimum $\mathrm{pH}$ for both $\mathrm{Gl}$ and amylase was found to be 7.0 (Fig. 11a, b). The Gl was found to be considerably active at the $\mathrm{pH}$ range of $6-8$. Kovalenko et al. [32] also reported the optimum $\mathrm{pH}$ for $\mathrm{Gl}$ activity from Actinoplanes missouriensis to be 7.0. Earlier studies have reported that amylase from Streptomyces sp. is active between $\mathrm{pH}$ of 6 and 7 [29]. Naragani et al. [33] reported maximum amylase activity from Streptomyces cheonanensis at $\mathrm{pH}$ 7.0. Singh et al. [34] also reported the optimum $\mathrm{pH}$ range of 6-7 for amylase activity of Streptomyces sp. MSC701.

\subsection{Kinetic properties of GI and amylase}

The Michaelis-Menten constant $\left(K_{\mathrm{m}}\right)$ for $\mathrm{Gl}$ and amylase was found to be $1.54 \mathrm{Mol}$ and $0.36 \mathrm{Mol}$, respectively. The Lineweaver-Burk plot showed that the maximum velocity $\left(V_{\text {max }}\right)$ for $\mathrm{Gl}$ and amylase is $11.76 \mathrm{U} / \mathrm{ml}$ and $33 \mathrm{U} / \mathrm{ml}$, respectively (Fig. 12a, b). It is difficult to compare kinetic values of reported by other researchers, as they used different concentration of substrate and different assay 

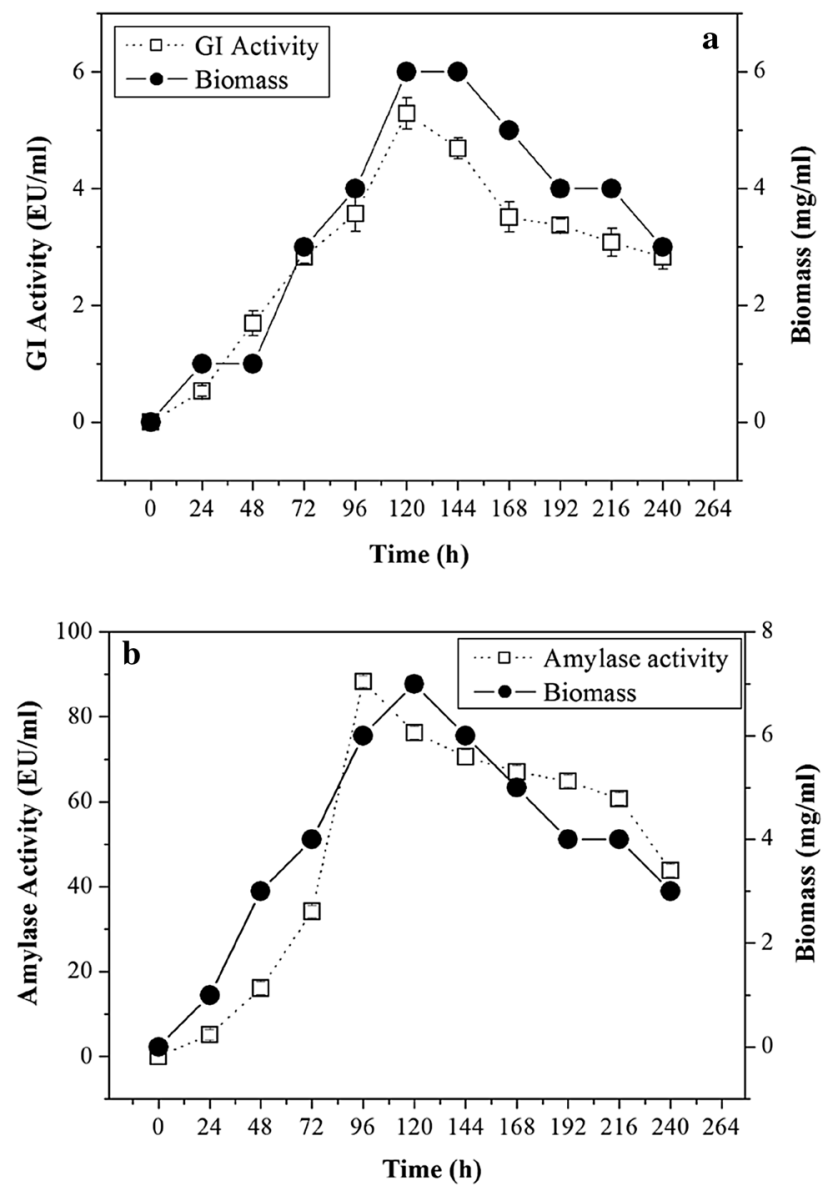

Fig. 9 a Optimum fermentation period for Gl production and growth pattern of isolate KP. b Optimum fermentation period for amylase production and growth pattern of isolate DM1

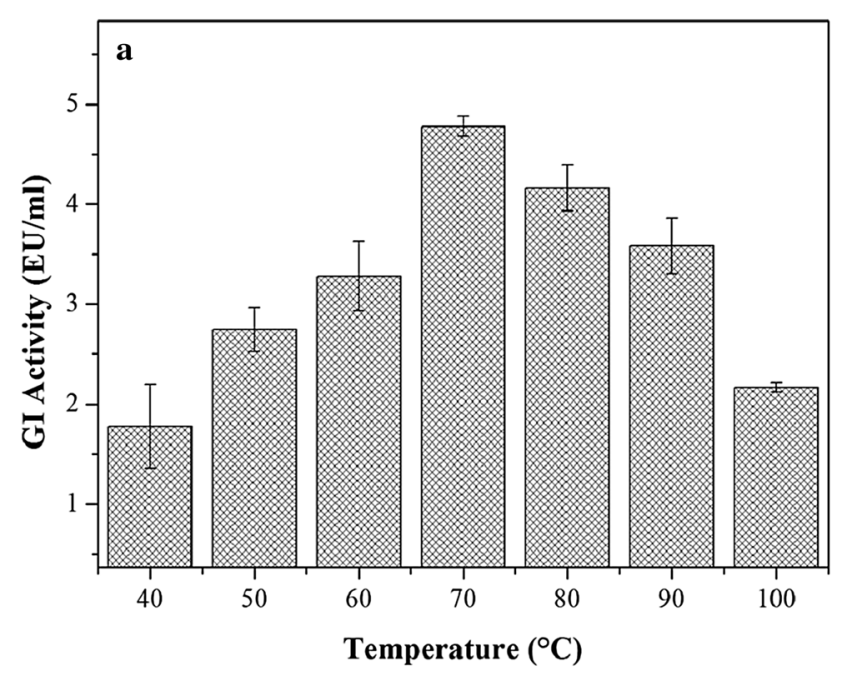

conditions. Fan et al. [35] reported $K_{\mathrm{m}}$ and $V_{\max }$ values for $\mathrm{Gl}$ to be $11 \mathrm{mM}$ and $25 \mathrm{U} / \mathrm{mg}$, respectively. The relatively low value of $K_{\mathrm{m}}$ for both the biocatalysts in the present study demonstrates higher affinity of enzyme for the substrate. Singh et al. [34] observed $K_{\mathrm{m}}$ and $V_{\max }$ values of amylase produced by Streptomyces sp. MSC702 to be $2.407 \mathrm{mg} / \mathrm{ml}$ and $21.853 \mathrm{~mol} / \mathrm{min} / \mathrm{mg}$, respectively.

\subsection{Production of HFCS}

The HFCS is produced from non-sweet sources like starch or cellulose. These initial polysaccharides are cheap and are available in abundance as agricultural residues [36]. The production of HFCS is carried out in two steps which involve hydrolysis of starch into glucose followed by isomerization into fructose [37].

In our investigation, we observed $90.9 \%$ hydrolysis of starch (Fig. 13a). This saccharification rate is appreciable as it is achieved using crude enzyme. Kaneko et al. [29] have reported around $90 \%$ yield of monosaccharides by breakdown of starch using purified amylases and optimizing the $\mathrm{pH}$. An isomerization of $40.8 \%$ was achieved using crude Gl from isolate KP (Fig. 13b). Researchers have reported conversions around 40\% [29] using purified enzyme. The isomerization step depends on the breakdown of starch polysaccharide into glucose units. The production of excessive dextrins, maltoses or other residual sugars during saccharification can decreases the efficiency of isomerization. Both the steps of HFCS production were carried out at similar pH which is advantageous as it cut down tedious procedures of $\mathrm{pH}$ alterations. We can still achieve better results using purified enzyme for the isomerizing reaction.

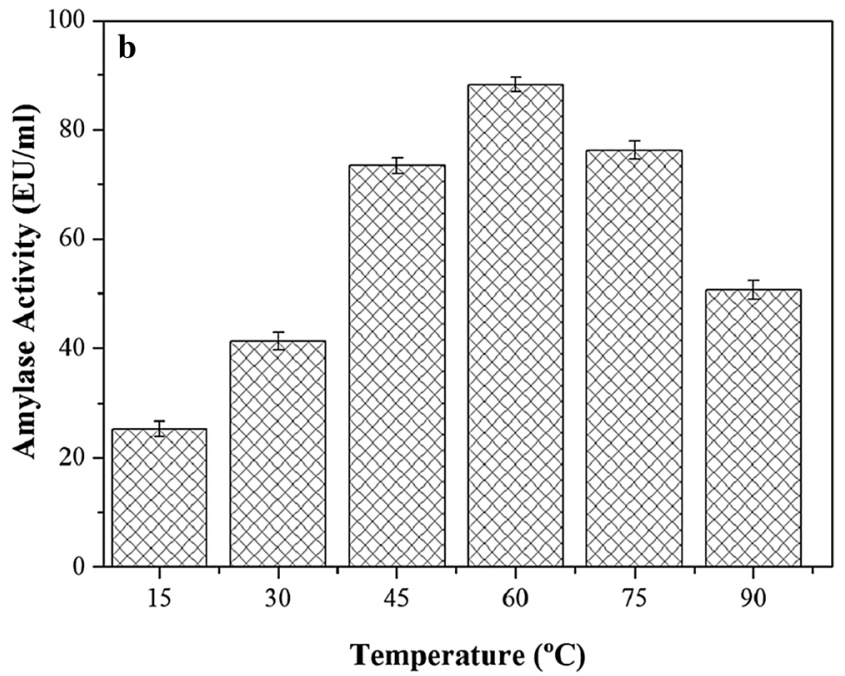

Fig. 10 a Effect of temperature on Gl activity. $\mathbf{b}$ Effect of temperature on amylase activity 

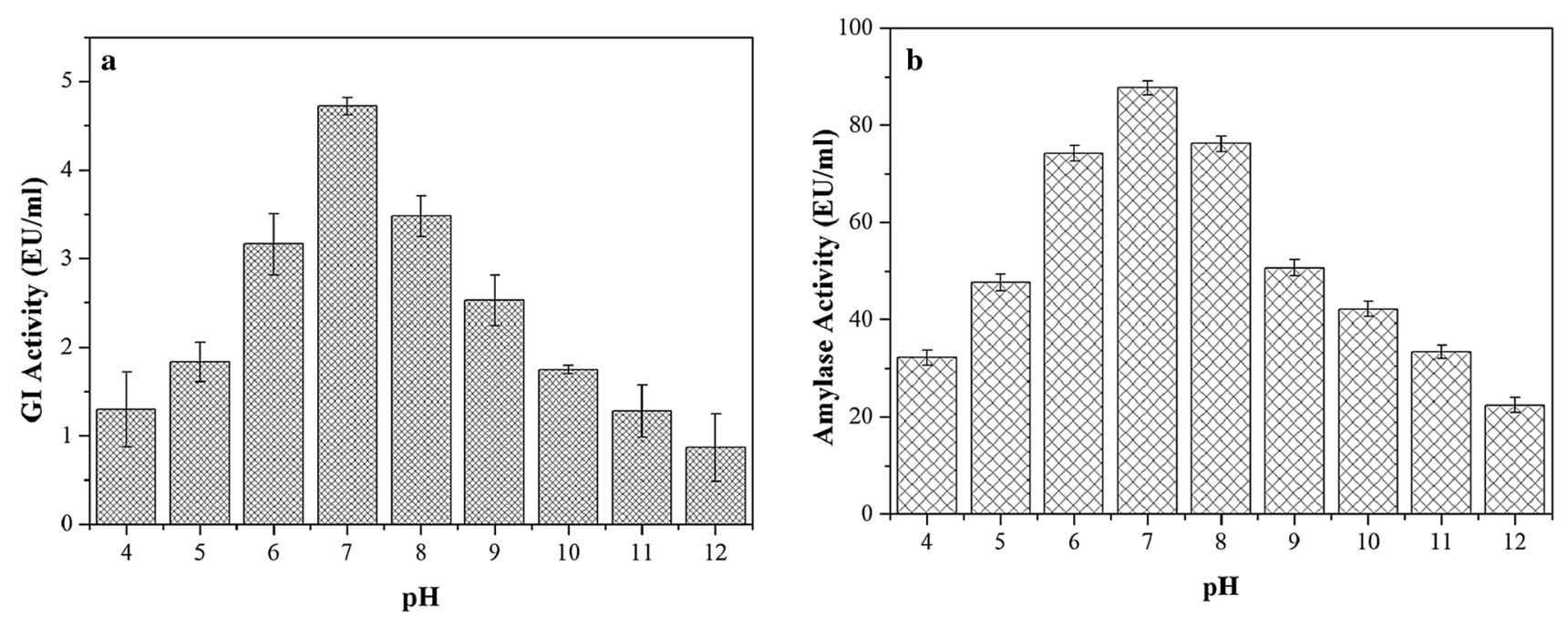

Fig. 11 a Effect of $\mathrm{pH}$ on $\mathrm{Gl}$ activity. $\mathbf{b}$ Effect of $\mathrm{pH}$ on amylase activity
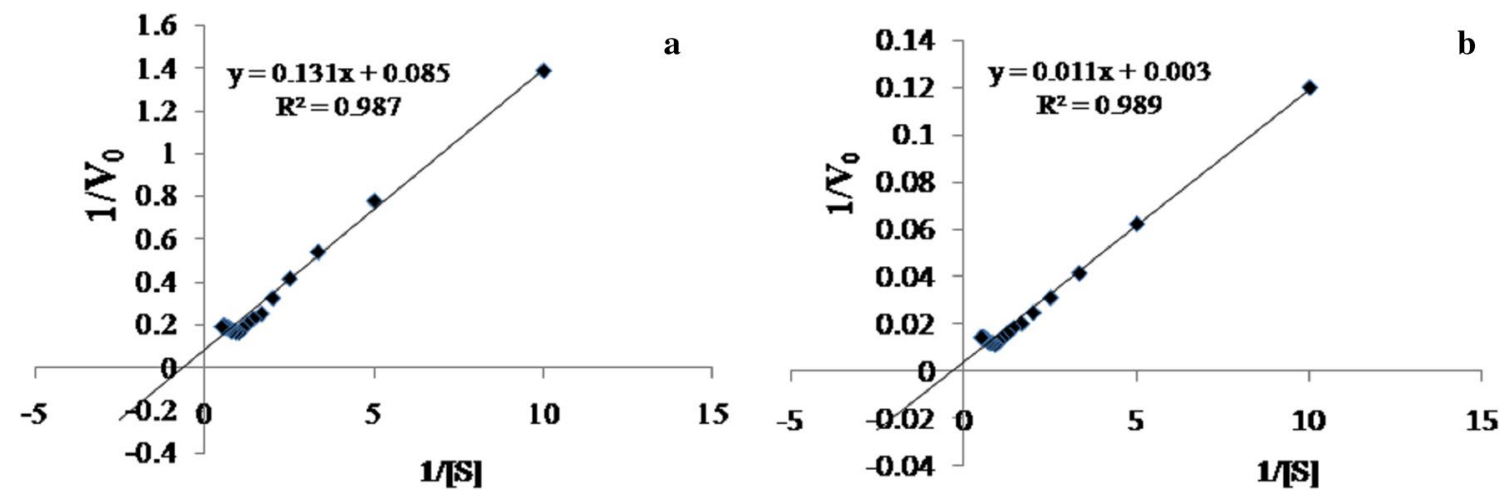

Fig. 12 a Lineweaver-Burk plot for GI under varying substrate concentration. b Lineweaver-Burk plot for amylase under varying substrate concentration
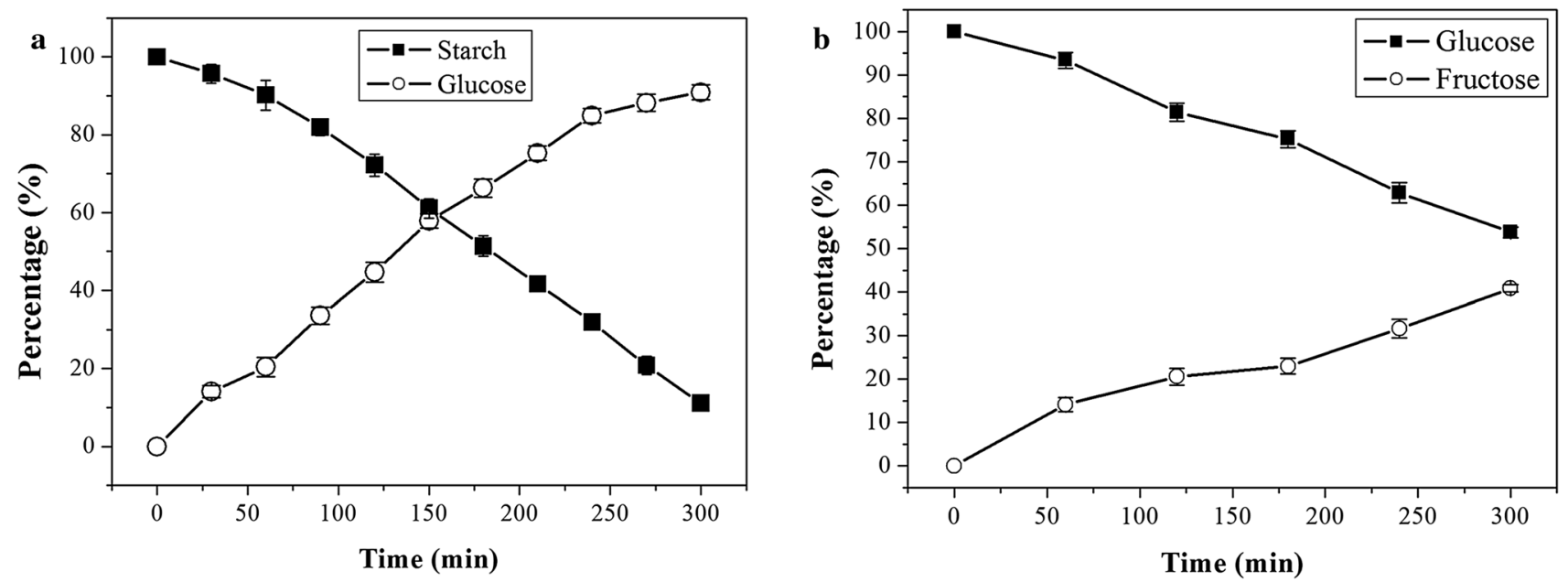

Fig. 13 a Hydrolysis of starch into glucose. b Isomerization of glucose into fructose 


\subsection{End product analysis using HPLC}

The HPLC analysis of HFCS revealed that it is composed of glucose and fructose. HPLC was found to be effective in detection and separation of sugars. The chromatogram revealed that the HFCS is comprised of a mixture of glucose and fructose (Fig. 14). The sharpness in peaks in our result indicates that a single molecule is eluted at a given retention time, and the HFCS is free from other impurities. The retention time of glucose was observed to be $\sim 15 \mathrm{~min}$ and that of fructose to be $\sim 18 \mathrm{~min}$ at the flow rate of $0.3 \mathrm{ml} / \mathrm{min}$ of solvent. The HPLC analysis confirmed that the end products formed during the HFCS production were glucose and fructose.

HFCS is a sweetener of today with wide applications in food, beverage, baking and pharmaceutical industries. Its advantages makes it a perfect alternative of sucrose or table sugar. In India, currently the HFCS has been imported majorly from different countries. Through this study, we intend to develop an indigenous technology for the production of HFCS using Streptomyces sp. HFCS gets absorbed in the body without the intervention of insulin which makes it suitable for use in diabetes [1]. Moreover, HFCS is a natural sugar derived from starch rich material which is converted enzymatically into HFCS without the addition of any chemicals or preservatives. HFCS has no side effects which is its another major advantage. It can be efficiently employed in bakery, canning and confectionary products and doesn't pose the problem of crystallization. Its sweetness is comparable with that of sucrose, as it also possess glucose and fructose in independent forms [35]. The table sugar or sucrose consumption on a daily basis risks the mental health causing impairment of incognitive functions and affecting decision making ability [3]. Apart from that, sucrose is also responsible for obesity and heartrelated problems. The current day sugarfree that are used in bakeries and confectionaries usually comprise aspartame that is not suitable for kids and phenylketonurics. Aspartame metabolites cause changes in hippocampus antioxidant defense system of brain causing damage to brain tissues [38]. The other sugarfree like stevia possesses a bitter taste. Fructo-oligosaccharides are also utilized as sugarfree, but their major drawback is that they are not naturally sweet and need to be combined with a sweet base like sucralose to be able to use as a sweetener.

The current scenario clearly indicates that there is a void in the market with respect to sugars which needs to be filled. The strong roots that sucrose have in our daily life need to be replaced with better alternative with lesser or no side effects. In this situation, HFCS is the key sweetener that can perfectly replace table sugar without compromising sweetness and with better and improved properties.

\section{Conclusion}

The advantages and widespread uses of HFCS in beverages, canning, bakery and confectionary industry make it most demanding sweetener of modern world. The implementation of enzyme is the most crucial step for HFCS production, and enzymes from different microbial sources have been tested for the better HFCS production. The present study reports the production of Gl from Streptomyces enissocaesilis for the first time. It exhibits significant isomerization rate of $40 \%$ in crude form and without optimization which is comparable to purified enzyme reported

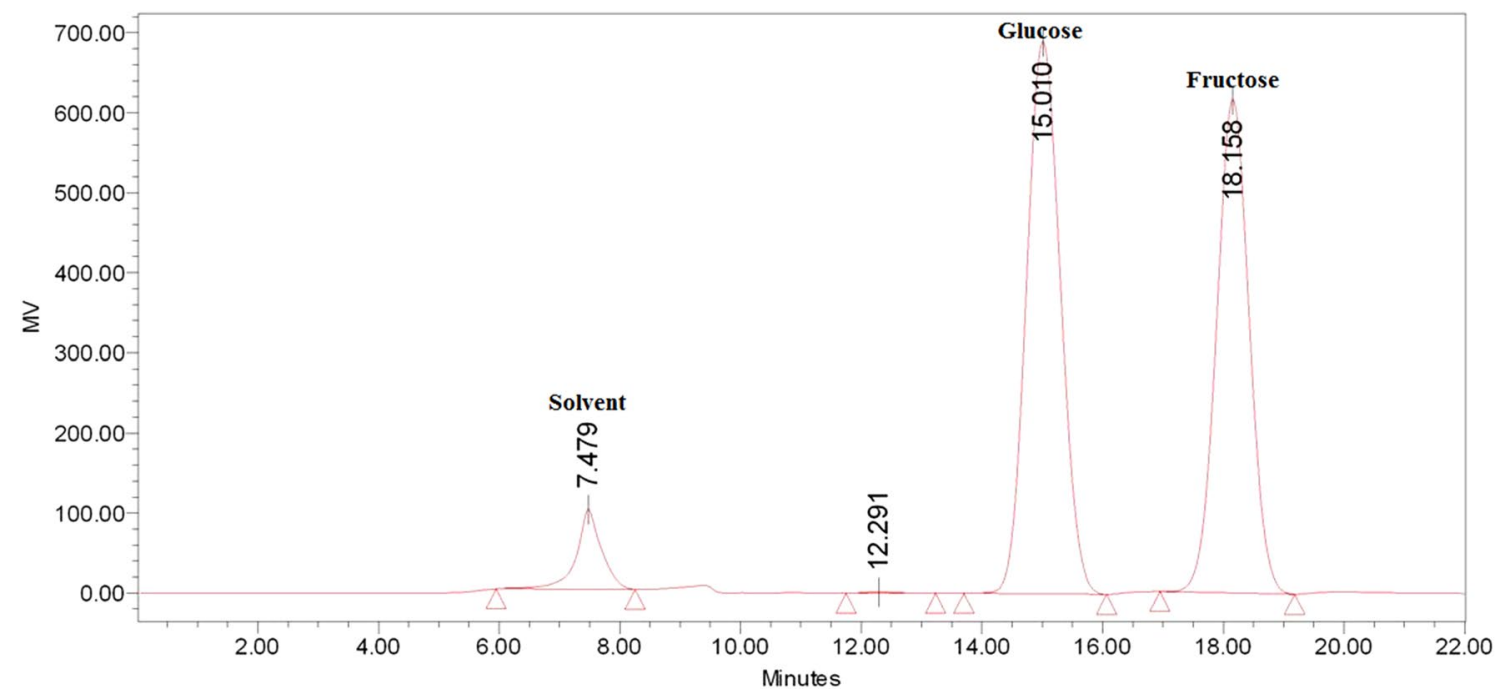

Fig. 14 HPLC chromatogram of HFCS produced using amylase and GI 
by other researchers. A drastic increase in saccharification and isomerization after optimization is expected which will prove the technique to be highly economical. Here, we also emphasize on the significant rate of isomerization at $70{ }^{\circ} \mathrm{C}$ as compared to commercially available $\mathrm{Gl}$ which has lower temperature optima. The industrial processes require enzymes working at high temperatures; therefore, applicability of newly reported $\mathrm{Gl}$ is high. Our study also accentuates on extracellular production of $\mathrm{Gl}$ as compared to other reports on intracellular production which further is an advantage for increasing the economic viability.

Both the steps involved in HFCS production were efficiently carried out at the same $\mathrm{pH}$. This advantage can be exploited at industrial scale as it reduces the cost and efforts of manipulating $\mathrm{pH}$ at different stages. This study might open new doors for the establishment of HFCS industries in India.

Acknowledgements The authors are thankful to Madhya Pradesh Council of Science and Technology, Bhopal (M.P.), India, for the financial assistance and Maharaja Ranjit Singh College of Professional Sciences, Indore (M.P.), for providing elaborate infrastructure to conduct the study. The authors sincerely thank the Sophisticated Instrumentation Center, Dr. Hari Singh Gaur Central University, Sagar (M.P.), for providing SEM facility and Dr. Naveen Kango and his student Bhanu Pratap Prajapati for HPLC analysis.

Authors contributions TAS conducted the research and wrote the paper. AJ analyzed the data, and SB designed the experiments. TAS, $A J$ and SB drafted the final manuscript. All authors have read and approved the manuscript.

Funding This study was supported by Madhya Pradesh Council of Science and Technology, Bhopal (M.P.), India.

Data availability All data generated or analyzed during this study are included in this published article.

Conflict of interest The authors declare that they have no conflict of interest.

Ethics approval and consent to participate This article does not contain any studies with human participants or animals performed by any of the authors.

Consent for publication Not applicable.

\section{References}

1. Bhosale SH, Rao MB, Deshpande VV (1996) Molecular and industrial aspects of glucose isomerase. Microbiol Rev 60:280-300

2. Singh I, Langyan S, Yadava P (2014) Sweet corn and corn-based sweeteners. Sugar Tech 16:144-149

3. El-Shinnawy NA, Abd-Elmageid SA, Saber AM (2019) Effect of long term consumption of sucrose, aspartame and stevia sweeteners on hippocampus antioxidant defense status. Eur J Biomed Phar Sci 6:69-76
4. Prithviraj L, Schmitz A (2013) Sugar and high fructose corn syrup consumption shifts: change in tastes correlative prices. Int Sugar J 115:556-559

5. Ge Y, Wang Y, Zhou H, Wang S, Tong Y, Li W (1999) Coimmobilization of glucoamylase and glucose isomerase by molecular deposition technique for one-step conversion of dextrin to fructose. J Biotechnol 67:33-40

6. Ferder L, Ferder MD, Inserra F (2010) The role of high fructose corn syrup in metabolic syndrome and hypertension. Curr Hypertens Rep 12:105-112

7. Johnson R, Padmaja G, Moorthy SN (2009) Comparative production of glucose and high fructose syrup from cassava and sweet potato roots by direct conversion techniques. Innov Food Sci Emerg Technol 10:616-620

8. Chanitnun K, Pinphanichakarn P (2012) Glucose (xylose) isomerase production by Streptomyces sp. $\mathrm{CH} 7$ grown on agricultural residues. Braz J Microbiol 43:1084-1093

9. Bhasin S, Modi HA (2013) Streptomycetes: a storehouse of bioactive compounds and enzymes $A$ : production of glucose isomerase. Res J Recent Sci 2:330-339

10. Abd-Elhalem BT, El-Sawy M, Gamal RF, Abou-Taleb KA (2015) Production of amylases from Bacillus amyloliquefaciens under submerged fermentation using some agro-industrial by-products. Ann Agric Sci 60:193-202

11. Debnath M, Majumdar SK (1985) Glucose isomerase activity of Streptomyces kanamyceticus. Biotechnol Lett 7:373-375

12. Lobanok AG, Sapunova LI, Dikhtievski YO, Kazakevich IO (1998) Screening of glucose isomerase producing microorganisms. World J Microbiol Biotechnol 14:259-262

13. Srih-Belghith K, Bejar S (1998) A thermostable glucose isomerase having a relatively low optimum $\mathrm{pH}$ : study of activity and molecular cloning of the corresponding gene. Biotechnol Lett 20:553-556

14. Hasal P, Cejkova A, Vojtisek V (1992) Glucose isomerase production by Streptomyces sp. CCM 4102. Folia Microbiol 37:365-371

15. Haritha R, Siva Kumar K, Jagan Mohan YSYV, Ramana T (2010) Amylolytic and proteolytic actinobacteria isolated from marine sediments of Bay of Bengal. Int J Microbiol Res 1:37-44

16. Acharyabhatta A, Kandula SK, Ramana T (2013) Taxonomic and polyphasic characterization of alkaline amylase producing marine actinomycetes Streptomycetes rochei BTSS101. Int J Microbiol 2013:276921. https://doi.org/10.1155/2013/276921

17. Raghunathan R, Padhmadas R (2013) Production, purification and characterization of a-amylase using Streptomyces spp. PDS1 and Rhodococcus spp. isolated from Western Ghats. Int J Curr Microbiol Appl Sci 2:206-214

18. Chen WP, Anderson AW, Han YW (1979) Production of glucose isomerase by Streptomyces flavogriseus. Appl Environ Microbiol 37:324-331

19. Dische Z, Borenfreund E (1951) A new spectrophotometric method for the detection and determination of keto sugars and trioses. J Biol Chem 192:583-587

20. Clarridge JE (2004) 3rd Impact of 16S rRNA gene sequence analysis for identification of bacteria on clinical microbiology and infectious diseases. Clin Microbiol Rev 17:840-862

21. Manhas RK, Bala S (2004) Thermostable glucose isomerase production by some bacteria and Streptomyces. Indian J Microbiol 44:129-132

22. Kasumi T, Hayashi K, Tsumura N, Takagi T (1981) Physicochemical characterization of glucose isomerase from Streptomyces griseofuscus, S-41. Agric Biol Chem 45:1087-1095

23. Chen J, Xue QH, McErlean CSP, Zhi JH, Ma YQ, Jia XT, Zhang M, Ye XX (2016) Biocontrol potential of the antagonistic microorganism Streptomyces enissocaesilis against Orobanche cumana. Biocontrol 61:781-791 
24. Ganesan P, Anand S, Sivanandhan S, David RHA, Paulraj MG, AlDhabi NA, Ignacimuthu S (2018) Larvicidal, ovicidal and repellent activities of Streptomyces enissocaesilis (S12-17) isolated from western ghants of Tamil Nadu, India. J Entomol Zool Stud 6:1828-1835

25. Dhungel B, Subedi M, Tiwari KB, Shrestha UT, Pokhrel S, Agrawal VP (2007) Thermostable glucose isomerase from psychotolerant Streptomyces species. Int J Life Sci 1:6-10

26. Salahuddin K, Prasad P, Kumar S, Visavadia MD (2011) Isolation of soil thermophilic strains of actinomycetes for the production of a-amylase. Afr J Biotechnol 10:17831-17836

27. Selvam K, Vishnupuri B, Bose VSC (2011) Screening and quantification of marine actinomycetes producing industrial enzymes amylase, cellulase and lipase from south coast India. Int Pharma Biol Archiv 2:1481-1487

28. Jia D, Wang T, Liu Z, Jin L, Li J, Liao C, Chen D, Zheng Y (2018) Whole cell immobilization of refractory glucose isomerase using tris (hydroxymethyl) phosphine as crosslinker for preparation of high fructose corn syrup at elevated temperature. J Biosci Bioeng 126:176-182

29. Kaneko T, Takahashi S, Saito K (2000) Characterization of Acid stable glucose isomerase from Streptomyces sp., and development of single step processes for high-fructose corn sweetener (HFCS) production. Biosci Biotechnol Biochem 64:940-947

30. Yassien MA, Asfour HZ (2012) Improved production, purification and some properties of a-amylase from Streptomyces clavifer. Afr J Biotechnol 11:14603-14611

31. Nithya K, Muthukumar C, Kadaikunnan S, Alharbi NS, Khaled JM, Dhanasekaran D (2017) Purification, characterization and statistical optimization of a thermostable a-amylase from desert actinobacterium Streptomyces fragilis DA7-7. Biotechnology 7:350. https://doi.org/10.1007/s13205-017-0981-5
32. Kovalenko GA, Perminova LV, Chuenko TV, Sapunova LI, Shlyakhotko EA, Lobanok AG (2011) Immobilization of a recombinant strain producing glucose isomerase inside $\mathrm{SiO}_{2}$-xerogel and properties of prepared biocatalysts. Appl Biochem Microbiol 47:168-175

33. Naragani K, Vijayalakshmi M, Munaganti RK, Hima Bindu BSSN (2015) Studies on optimization of amylase production by Streptomyces cheonanensis VUK-A isolated from mangrove habitats. J Adv Biol Biotechnol 3:165-172

34. Singh R, Kapoor V, Kumar V (2011) Influence of carbon and nitrogen sources on the a-amylase production by a newly isolated thermotolerant Streptomyces sp. MSC702 (MTCC 10772). Asian J Biotechnol 3:540-553

35. Fan L, Zhang Y, Wang WQJ, Shao W (2011) Cloning and analysis of the xylAB operon and characterization of xylose isomerase from Thermoanaerobacter ethanolicus. Biotechnol Lett 33:593-598

36. Crabb WD, Shetty JK (1999) Commodity scale production of sugars from starches. Curr Opin Microbiol 2:252-256

37. White JS (2008) Straight talk about high fructose corn syrup: what it is and what it ain't. Am J Clin Nutr 88:1716S-1721S

38. Onaolapo AY, Onaolapo OJ, Nwoha PU (2017) Aspartame and the hippocampus: revealing a bidirectional, dose/timedependent behavioural and morphological shift in mice. Neurobiol Learn Mem 139:76-88

Publisher's Note Springer Nature remains neutral with regard to jurisdictional claims in published maps and institutional affiliations. 